\title{
O Sistema Mineiro de Avaliação da Educação Pública: a percepção dos profissionais das escolas públicas estaduais de Belo Horizonte
}

\author{
Stella Willians de Carvalho ${ }^{1}$ \\ stelacarvalho2002@yahoo.com.br
}

Jussara Maria de Pinho Magalhães Penna ${ }^{2}$

jussarapenna@gmail.com

Elias José Lopes de Freitas ${ }^{3}$

eliasjlf@ig.com.br

Maria José Pereira ${ }^{4}$

marijp52@gmail.com

Ofélia de Souza Vieira

ofmth@yahoo.com.br

Resumo

Este artigo analisa os resultados da pesquisa "O olhar das escolas públicas estaduais de Minas Gerais para os resultados do SIMAVE", desenvolvida pelo Núcleo de Estudos e Pesquisas sobre Políticas Educacionais da FaE/UEMG, que trata da centralidade das avaliações sistêmicas no cenário educacional brasileiro e suas implicações

1 Professora da FaE/UEMG.

2 Professora da FaE/UEMG.

3 Professor da FaE/UEMG e da Rede Municipal de Belo Horizonte.

4 Professora da FaE/UEMG.

5 Professora da FaE/UEMG. 
para a prática pedagógica dos sujeitos que atuam na escola: diretores, coordenadores e professores. Inicialmente, pretende-se discutir o processo de implementação das avaliações sistêmicas no país a partir do resgate da conjuntura histórica mundial e brasileira. Em seguida, focaliza-se a percepção dos sujeitos envolvidos nas escolas no processo de avaliação do SIMAVE.

Palavras-Chave: avaliação sistêmica; política educacional; reforma educacional; instituição escolar.

\section{Introdução}

As avaliações sistêmicas, universo no qual se insere o Sistema Mineiro de Avaliação da Educação Pública (SIMAVE), são uma das mais recentes e controversas iniciativas do poder público em termos de política educacional. De um lado, estão aqueles que as defendem, afirmando sua importância na garantia da eficiência do sistema no que se refere à aquisição de competências básicas pelos alunos. De outro, estão aqueles que as criticam, apontando-as como passíveis de homogeneização e controle pelo poder central do conteúdo curricular das escolas. Divergências a parte, o que se sabe é que tais avaliações têm estado presentes em vários sistemas de ensino, como acontece frequentemente nas escolas da cidade de Belo Horizonte. Elas passaram a nortear a gestão educacional no sentido de apontar em que aspectos devem ser investidos maiores esforços para o alcance de melhores resultados no processo de ensino-aprendizagem. Por essa razão, não se pode mais desconsiderar o estudo dessa política quando se pretende entender a gestão dos sistemas educacionais na atualidade.

Mas, se por um lado, as avaliações sistêmicas têm sido uma ferramenta de gestão das instâncias centrais, a divulgação dos seus resultados acaba por remeter-nos à outra ponta do processo educacional: a escola. Um dos efeitos das avaliações sistêmicas é ensejar um olhar para a escola como uma das responsáveis pelo bom ou mau resultado conseguido nessas aferições. Cabem aí algumas perguntas: como aqueles que se inserem dentro da escola, seja como gestores ou professores, percebem 
os resultados dessas avaliações? Até que ponto esses atores veem esses resultados como consequência de suas condutas pedagógicas? Até que ponto tais resultados norteiam modificações e transformações nos seus projetos pedagógicos?

Este artigo é resultado de pesquisa que pretende dirigir tais questionamentos para o processo específico do SIMAVE, em escolas da cidade de Belo Horizonte (MG) que integram o projeto "Escola Viva, Comunidade Ativa". As escolas pesquisadas foram selecionadas de forma aleatória, contemplando as metropolitanas A, B e C, que são responsáveis pela organização e funcionamento das escolas públicas na região metropolitana de Belo Horizonte. Entende-se que a interação na forma de aceitação, rejeição, apoio ou crítica, dos atores envolvidos nas políticas públicas influencia a trajetória das escolas, determinando seus avanços ou recuos.

A metodologia adotada para a investigação foi a pesquisa de campo, acompanhada de pesquisa bibliográfica e documental. A coleta de dados se deu por meio de entrevista semiestruturada e observação sistemática não participante nas escolas selecionadas. A análise e a discussão dos dados resultaram em um texto descritivo e analítico das categorias e dos atores envolvidos: diretores, coordenadores (incluindo-se supervisores e orientadores) e professores.

\section{Revisão de literatura}

\subsection{As políticas públicas}

Segundo Azevedo (1997), o Estado ganha visibilidade e materialidade através da adoção de determinadas medidas, as quais podem ser chamadas de políticas públicas. A autora parte desse pressuposto para argumentar que o Estado, através de suas estratégias, diante de determinados problemas, tentará impor um modelo de organização social de acordo com a orientação dos grupos que nele ocupam posições estratégicas. Deutsch (1984) lembra que as políticas públicas, apesar de formuladas pelo Estado, refletem os conflitos entre os vários grupos de interesses que compõem a sociedade. 
De acordo com Azevedo (1997), a formulação de tais políticas emerge da existência de determinadas questões que passam a ser discutidas pela sociedade através de alguns de seus grupos que conseguem dar a elas o status de uma questão socialmente problematizada e que passa a exigir especial atenção do poder público. A satisfação dessas expectativas daria legitimidade ao poder público, facilitando a governabilidade. As políticas públicas seriam, portanto, as políticas tomadas pelo Estado que tenham por objeto o público. Em outras palavras, as políticas públicas nasceriam das demandas de determinados grupos que, por sua mobilização, inserem-nas na agenda governamental.

Deve-se ressaltar que, por essa razão, as políticas públicas assumirão a marca dos grupos que ocupam posições estratégicas, tanto dentro da sociedade civil quanto do aparato burocrático responsável pela sua formulação e implementação. Ressalte-se, também, o papel daqueles setores responsáveis pela sua execução que, certamente, poderão influir nos seus contornos finais.

Estudar a relação de forças presentes entre os grupos que compõem a sociedade civil permite, como defendia Gramsci (1978), compreender os caminhos traçados na sociedade política, já que os grupos hegemônicos presentes na primeira estariam em condição de exercer grande influência na tomada de decisão pela sociedade política. Mesmo o aparato burocrático responsável pela implementação das políticas estaria sob a influência desses grupos hegemônicos.

É importante assinalar que mesmo os grupos que, aparentemente, não têm poder de influir na formulação e na implementação das políticas não se silenciam e, através de alguns atos, mostram sua posição de oposição ou não concordância a elas. Dessa forma, quando da operacionalização de uma política pública, esta poderá avançar ou não de acordo com o que pensam os grupos que com ela lidarão nessa etapa. Segundo Bonetti (2006, p. 76):

[...] as pessoas, todavia, que entram em contato com as políticas públicas no decorrer de suas longas trajetórias, não pensam de modo uniforme, não têm a mesma interpretação de intervenção na realidade. As políticas públicas, ao longo de seus percursos, são contaminadas por interesses, inocências e sabedorias. 
Dessa forma, tem-se que as políticas públicas nascem para a solução, por parte do Estado, daquilo que chamamos de questões socialmente problematizadas, trazem em si a marca de grupos hegemônicos dentro da sociedade, grupos esses que influenciam sua formulação e operacionalização, e dependem, em última instância, da concordância dos grupos responsáveis por sua implementação.

No caso das políticas educacionais, deve-se considerar que elas articulam-se ao projeto de sociedade que os grupos hegemônicos pretendem implantar ou que está em curso, em cada momento histórico ou em cada conjuntura, projeto esse que corresponde ao referencial global de uma sociedade.

Tal projeto de sociedade é construído pelas forças sociais, globais, nacionais e locais que têm poder de voz e de decisão e que, por isso, fazem chegar seus interesses até o Estado e a máquina governamental, influenciando a formulação e a implementação das políticas ou dos programas de ação. “O cotidiano escolar, portanto, representa o elo final de uma complexa cadeia que se monta para dar concretude a uma política - a uma policy - entendida aqui como um programa de ação" (AZEVEDO, 1997, p. 59).

\subsection{As políticas educacionais brasileiras nos últimos anos do século XX}

\subsubsection{Os problemas da evasão e da repetência}

Pode-se afirmar que nas décadas de 70 e 80 tornou-se realidade a universalização do ensino público, fruto de uma luta iniciada em meados do século XX. Esse processo representou, sem dúvida, um grande passo para a democratização da educação no país e ganhou visibilidade com a chegada da escola às periferias dos grandes centros urbanos. Isso significou a incorporação de grandes contingentes da população, notadamente as classes populares.

A expansão quantitativa da rede pública trouxe consigo uma nova realidade, a de que as classes populares não conseguiam seguir a trajetória escolar tida como ideal, isto é, a superação de todas as etapas 
previstas na escolarização. Os números da Pesquisa Nacional por Amostra de Domicílios (PNAD), referentes ao censo realizado pelo IBGE em 1982, atestam isso, mostrando a incidência da repetência entre os grupos menos favorecidos economicamente:

\section{TABELA 1}

Incidência de repetência escolar no Brasil e em grupos econômicos diversos - 1982

\begin{tabular}{c|c|c|c|c}
\hline Série Escolar & Brasil & $\begin{array}{c}\text { Sudeste } \\
\text { urbano de } \\
\text { renda alta }\end{array}$ & $\begin{array}{c}\text { Centro-Oeste } \\
\text { urbano de renda } \\
\text { baixa }\end{array}$ & $\begin{array}{c}\text { Nordeste } \\
\text { rural de } \\
\text { renda baixa }\end{array}$ \\
\hline 1a & 53,7 & 37,4 & 63,6 & 73,9 \\
$2 a$ & 33,4 & 24,7 & 38,9 & 52,4 \\
3a & 25,9 & 23,3 & 21,5 & 50,4 \\
$4 a$ & 20,4 & 17,3 & 23,1 & 48,7 \\
$5 a$ & 30,4 & 30,4 & 49,0 & 48,4 \\
$6 a$ & 17,2 & 23,0 & 46,4 & 25,5 \\
$7 a$ & 14,2 & 16,1 & 13,7 & 38,6 \\
$8 a$ & 15,4 & 13,6 & 49,6 & 55,8 \\
\hline
\end{tabular}

Fonte: Modelo Profluxo aplicado aos dados PNAD 82.

A TAB. 1, além de evidenciar o prejuízo na escolarização de determinados grupos da população, ainda aponta os gargalos da trajetória escolar como sendo o $1^{\circ}$ e o $5^{\circ}$ ano da escolarização. Os números confirmam que a democratização do acesso não propiciou as condições de permanência dos grupos recém-chegados à escola. Essa seria a outra face do processo de democratização do ensino, a questão da permanência, ou, como afirma Arelaro (1988, p. 38), “[...] o desafio da permanência na escola da maioria da população constitui-se, hoje, a questão crucial da educação [...]".

Essas questões passaram a ser debatidas no Brasil por intelectuais, buscando colocar o problema na ordem do dia. Weber (2003), ao analisar o referido contexto, constatou o surgimento de duas posições: uma que apontava a escola como modelo de reprodução social e responsável pelo quadro de evasão e de repetência. Nessa direção, autores como Arroyo (1992), Arelaro (1988) e Campos (1983) procuraram associar o quadro da 
exclusão escolar a um quadro mais amplo da exclusão social relacionada ao sistema econômico. Para esses autores, o fracasso escolar não é um fenômeno individual ligado a aptidões e capacidades, mas um fenômeno social que atinge determinada classe, sendo os mecanismos da escola partes ativas do processo.

Outra corrente de pensamento irá destacar a necessidade de se reorientar a gestão dos sistemas escolares como forma de diminuir a sua baixa produtividade. Segundo essa corrente, se fossem colocadas metas e avaliados os resultados, haveria possibilidade de um diagnóstico mais preciso do contexto educacional, o que orientaria políticas públicas mais eficazes. Nesse sentido, tal perspectiva estaria mais preocupada com a eficiência e a eficácia do processo educacional. Uma das autoras que representam essa corrente de pensamento é Guiomar Namo de Mello, que atribui a baixa produtividade do sistema aos fatores ligados a um padrão caótico de gestão, como: a ausência de planejamento estratégico no nível federal e de um regime de colaboração entre União, estados e municípios; a centralização e a verticalização das decisões resultando na falta de autonomia e no enfraquecimento da escola; a irracionalidade e o clientelismo na expansão da rede física; a ausência de uma política racional de recursos humanos. Além do mais, defende uma readequação da gestão interna da escola (MELLO, 1992).

Essas duas posições que se ocupavam da mesma problemática, embora tivessem para ela soluções diferenciadas, orientarão os debates e as políticas educacionais surgidas nos anos 80 e 90.

Em 1991, surge em Minas Gerais o "Pró-Qualidade", uma política que apostava na eficiência e na eficácia da gestão pública como forma de dotar o sistema educacional de uma maior produtividade, paradigmas que nortearão, também, as políticas educacionais implementadas pelo poder central (MEC) a partir de 92. Weber (2003) assinala que a implantação dos Parâmetros Curriculares Nacionais (PCNs) e das avaliações sistêmicas, além da própria LDB, são parte desse processo em que o poder administrativo central, MEC, assume a condução de políticas educacionais, dando a elas uma nova configuração.

Os princípios norteadores dessas políticas se ancoravam nas ideias 
surgidas no contexto de transnacionalização da economia que, segundo Weffort (1992), criava um novo sistema produtivo mundial em que fábricas poderiam atravessar fronteiras de um país para outro, sendo os recursos básicos de cada nação as habilidades e as ideias de seus cidadãos.

\subsubsection{A conjuntura econômica mundial do fim do século XX e as reformas educacionais}

Assistiu-se, no fim do século $X X$, à emergência de uma sociedade pautada pela variedade e pelo volume de informações e inovações cotidianas que obrigaram os indivíduos a tomar muitas decisões no seu dia a dia frente às demandas do mercado de trabalho. Atualmente, mudanças profundas ocorrem nos campos econômico, sócio-cultural, ético-político, ideológico e teórico. A face do mundo hoje é outra, uma vez que existe uma cartografia geopolítica diferente, determinada por fatores como a globalização e a reestruturação do Estado.

A educação, como um fenômeno social, não ficou isenta dessa revolução, sendo o seu papel e as suas funções questionados como elementos fortes nessa etapa de mudanças, como destacam Frigotto e Ciavatta (2003, p. 97): “[...] ocorre uma disputa entre o ajuste dos sistemas educacionais às demandas da nova ordem do capital e às demandas por uma efetiva democratização do acesso ao conhecimento em todos os níveis".

A relação existente entre a mundialização e as reformas educacionais é discutida por Cardoso (1999) da seguinte forma: o impacto sobre a organização do trabalho passa a exigir maior qualificação do trabalhador; os governos aumentam as despesas com a educação, a fim de ter um sistema educacional bem-estruturado; a comparação entre os diferentes países sobre a qualidade dos sistemas educacionais força os sistemas a buscarem os mesmos padrões; a utilização da informática e da educação a distância como forma de baratear os custos e atingir maior número de pessoas; a internet como forma de globalizar as informações e a educação.

A partir dessa realidade, os organismos internacionais passam a determinar as metas que os países devem atingir também no âmbito da educação. Nesse cenário, as políticas educacionais passam a ser desenhadas segundo critérios internacionais. As reformas tornam-se 
intencionais com objetivos determinados pelos organismos multilaterais que, visando ao crescimento econômico, procuram alinhar a escola à empresa e os conteúdos ensinados às exigências do mercado.

A partir do final da década de 80, as reformas na educação, impactadas pelas mudanças econômicas impostas pela globalização, passaram a exigir maior eficiência e produtividade dos trabalhadores de modo a se adaptarem mais facilmente às exigências do mercado. Essas reformas apresentam um objetivo político bem definido que envolve a estrutura administrativa e pedagógica da escola, a formação de professores, os conteúdos a serem ensinados, os aportes teóricos a serem adotados, enfim, tudo o que possa estar relacionado com o processo de ensino-aprendizagem.

Nesse contexto, as reformas educacionais se apresentam como ferramenta de desenvolvimento econômico e, como política pública, passam a ser compreendidas como instrumento usado pelo Estado para manter as bases de funcionamento do sistema de acumulação. Isso reforça a tese de regulação social como controle, mas também aponta na direção de ajuste estrutural exigido pelos organismos multilaterais aos países com dívidas externas, como forma de garantir o pagamento delas.

Nas reformas educacionais, tem papel preponderante a atuação de organismos internacionais mediante o patrocínio de grandes eventos no âmbito educacional, a oferta de assessorias técnicas para auxiliar na reestruturação da legislação no campo da educação e do trabalho, bem como na elaboração de materiais teóricos que visam a argumentar a favor da necessidade e da urgência dessas mudanças.

O primeiro evento que inaugurou um grande projeto de educação em nível mundial realizou-se em Jomtien, na Tailândia, em 1990, sob o título "Conferência Mundial sobre Educação para Todos". Esse evento foi financiado pela Organização para a Educação, a Ciência e a Cultura das Nações Unidas (UNESCO), pelo Programa das Nações Unidas para o Desenvolvimento (PNUD), pelo Fundo das Nações Unidas para a Infância (UNICEF) e pelo Banco Mundial. Participaram da reunião de Jomtien, além de representantes de 155 governos, agências internacionais, organizações não governamentais, associações de profissionais e personalidades na área da educação em nível mundial. 
A conferência de Jomtien apresentou uma proposta de educação para o decênio de 90, tendo como objetivo principal a satisfação das necessidades básicas de aprendizagem:

Cada pessoa - criança, jovem ou adulto - deverá estar em condições de aproveitar as oportunidades educacionais oferecidas para satisfazer suas necessidades básicas de aprendizagem. Estas necessidades abarcam tanto as ferramentas essenciais para a aprendizagem (como a leitura e a escrita, a expressão oral, o cálculo, a solução de problemas), como os conteúdos básicos da aprendizagem (conhecimentos teóricos e práticos, valores e atitudes) necessários para que os seres humanos possam sobreviver e desenvolver plenamente suas capacidades, viver e trabalhar com dignidade, participar plenamente do desenvolvimento, melhorar a qualidade de sua vida, tomar decisões fundamentais e continuar aprendendo. A amplitude das necessidades básicas de aprendizagem varia de país a país, sua cultura muda inevitavelmente com o transcurso do tempo (ORGANIZAÇÃO PARA A EDUCAÇÃO, A CIÊNCIA E A CULTURA DAS NAÇÕES UNIDAS, 1990, p. 11).

A conferência apresentou documentos expedidos pelos organismos internacionais - como o Banco Mundial e a UNESCO -, apontando a educação básica como prioridade. A educação de base é definida no documento acima citado como sendo as habilidades e as competências gerais relativas à linguagem, à ciência, à matemática e à comunicação. Daí decorre a reestruturação dos currículos e dos programas e a criação de novos sistemas de avaliação.

Na década de 90, as orientações políticas do Banco Mundial para a educação brasileira recaíram sobre descentralização e a autonomia da gestão escolar, assegurando a presença da comunidade escolar e da sociedade civil e reduzindo as responsabilidades do Estado pelo sucesso ou fracasso educacional. Essas ideias já se delineavam desde a década de 80, quando os pressupostos da descentralização e da flexibilidade dos sistemas de ensino tornavam-se estratégias para a redução de custos na proposta neoliberal que se desenrolava. 
Dessa forma, são propostas avaliações externas à escola e a qualidade do ensino passa a ser medida a partir da ideia do rankeamento e da competitividade entre as instituições de ensino. Além disso, o Banco Mundial irá sugerir a utilização de modelos gerenciais que demonstram eficiência em setores da iniciativa privada para serem implementados nas escolas, como exemplos de gerenciamentos bem-sucedidos. A intenção seria a utilização dessas ferramentas para otimizar os processos educacionais, para erradicar a evasão e a repetência, vistas como provas da baixa produtividade da educação brasileira.

A racionalidade da eficiência e da eficácia presente nas teorias administrativas empresariais será importada pelas teorias pedagógicas, subsidiando as reformas da educação dos anos 90. Pereira citado por Oliveira (2001) argumenta que a recuperação da legitimidade burocrática foi encontrada na administração pública gerencial caracterizada pela transformação de agentes públicos em gerentes capazes de administrar recursos em favor de resultados desejáveis.

A gestão democrática da escola, entendida como processo de descentralização que responsabiliza os agentes locais pelos processos educacionais, torna-se um dos mecanismos dessas novas políticas em consonância com a reforma do setor público. As avaliações sistêmicas também ganham funcionalidade nesse contexto, já que seriam mecanismos indicadores da qualidade e da eficiência dos sistemas. A definição de qualidade da educação seria dada pelos resultados das avaliações sistêmicas que teriam como referência os PCNs.

\subsection{As avaliações sistêmicas - um breve histórico}

Denomina-se avaliação sistêmica aquela que é feita em larga escala, de forma padronizada, visando a aferir os conhecimentos obtidos pelos alunos com a finalidade de guiar a implementação de políticas públicas na educação. É conduzida pela instância governamental gestora dos processos educacionais atribuindo-se ao Estado, nesse caso, o papel de um Estado Avaliador. Esse tipo de avaliação permite o controle, pelas instâncias centrais, sobre o desenvolvimento do currículo, uma vez que 
tais processos terão como referência as diretrizes curriculares emanadas por elas. Segundo Mello (1992):

[...] a avaliação externa feita pela administração central ou por ela contratada, não substitui nem conflita com a avaliação realizada pela escola. Trata-se neste caso de um instrumento de gestão, cujo objetivo é analisar o desempenho do sistema como um todo e gerar informações que subsidiem decisões sobre alocação de recursos técnicos e financeiros. Enquanto a avaliação feita pela escola, que também deveria merecer uma profunda revisão, tem como um de seus objetivos tomar decisões sobre cada aluno individual, a avaliação externa visa a aferir o desenvolvimento de escolas, municípios, regiões e sistemas como um todo (MELLO, 1992, p. 100).

A mesma autora esclarece que os objetivos dessa avaliação não seriam avaliar alunos em particular, mas apontar pontos fortes e fracos do sistema como um todo, sendo que sem essa informação ela incorreria no risco de continuar tratando de forma homogênea os desiguais, aumentando as desigualdades escolares.

Na América Latina, o contexto histórico em que é formulado esse procedimento é o das reformas educacionais dos anos 90. No Brasil, a partir desse período, foi instituído um dos mais complexos modelos avaliativos do mundo, que vai do ensino fundamental até os cursos de pós-graduação. Nesse sistema temos: o Sistema Nacional de Avaliação da Educação Básica (SAEB); o Exame Nacional do Ensino Médio (ENEM); o Exame Nacional de Desempenho dos Estudantes (ENADE), dirigido ao ensino superior, além de iniciativas dos Estados da Federação, como Minas Gerais, que implantou o Sistema Mineiro de Avaliação da Educação Pública (SIMAVE).

No caso brasileiro, cabe ressaltar que os anos 90 acabaram por materializar em políticas algumas críticas feitas ao sistema educacional, como a sua baixa produtividade ilustrada nos altos índices de evasão e de repetência. Dessa forma, as reformas impetradas pelo poder público passaram a ter como objetivo corrigir tais distorções. A instituição de um sistema de avaliação seria uma das ferramentas utilizadas na melhoria 
da qualidade de ensino entendida como superação dos problemas apresentados pela educação no país.

\subsubsection{O SIMAVE - as avaliações externas em Minas Gerais}

Desde 1991, a avaliação externa das escolas mineiras tem sido parte integrante da política educacional estadual, preconizada pela Constituição do Estado de Minas Gerais, como garantia de um ensino de qualidade, conforme previsto na alínea a, do inciso X, de seu art. 196 (MINAS GERAIS, 2001). Torna-se, dessa forma, instituído o Programa de Avaliação Educacional da Escola Pública de Minas Gerais, conforme Resolução n. 6.908, de 18 de janeiro de 1992, do Secretário de Estado de Educação, Walfrido dos Mares Guia.

Em 1992, foi realizada a primeira experiência de avaliação, da qual participaram todas as escolas da rede estadual cujas crianças já tivessem completado o Ciclo Básico de Alfabetização (CBA). Os resultados obtidos compuseram relatórios com os seguintes elementos:

a) situação do alunado no que se refere aos conteúdos básicos de Português, Matemática e Ciências;

b) caracterização geral dos alunos: sexo, idade, situação de novatos e repetentes e aspectos relacionados ao seu ambiente familiar;

c) caracterização das escolas em relação aos profissionais que atuam no CBA e ao gerenciamento do ensino nas duas primeiras séries do ensino fundamental.

Em novembro de 1992, aconteceu a avaliação de rendimento dos alunos da $8^{a}$ série do ensino fundamental.

A partir de 2009, o Sistema Mineiro de Avaliação da Educação Pública (SIMAVE) passou a fazer parte dos Projetos Estruturadores do Estado, sendo que estes:

[...] nasceram do planejamento estratégico do atual Governo do Estado de Minas Gerais e consistem em ações prioritárias para o Governo, dentro do PMDI (Plano Mineiro de Desenvolvimento Integrado) e do PPAG (Plano Plurianual de Ação Governamental). Estes Projetos fazem parte do GERAES (Gestão Estratégica dos Recursos e Ações do Estado), 
conforme Artigo 23, Decreto 43.554/2003. O projeto estruturador é uma iniciativa que:

Transforma a visão de futuro em resultados concretos que sinalizam a mudança desejada.

Tem efeito multiplicador: capacidade de gerar outras iniciativas privadas ou públicas.

Mobiliza e articula recursos públicos, privados ou em parceria.

Produz a percepção da sociedade: "quem governa tem uma visão de futuro que está sendo construída, mediante ações concretas".

Organiza-se como um projeto, com foco bem definido, objetivo mensurável, ações, metas, prazos, custos, resultados esperados, que permitem um gerenciamento intensivo (MINAS GERAIS, 2004).

Parte do Projeto Estruturador está no Acordo de Resultados que visa à concretização, expressa por meio de indicadores, de compromissos assumidos pela Secretaria de Estado de Educação, pelas Superintendências Regionais de Ensino e pelas Escolas Estaduais. Em contrapartida, é concedido aos acordados, em caso de desempenho satisfatório, o pagamento de prêmio de produtividade aos servidores, como incentivo. Os diretores das escolas estaduais assinam um termo de compromisso, assumindo ter como meta a melhoria dos resultados educacionais de sua escola.

\section{SIMAVE: o olhar da escola para os seus resultados}

\subsection{Metodologia}

Na pesquisa optou-se por uma abordagem qualitativa, principalmente pelas possibilidades abertas comuns a esse tipo de investigação, que permite maior contato com o grupo investigado, além da estreita interação entre o investigador e o objeto da pesquisa.

Foram selecionadas escolas participantes do projeto "Escola Viva, Comunidade Ativa" da Secretaria de Estado da Educação de Minas Gerais (SEE/MG). Esse projeto é voltado para o fortalecimento de escolas em áreas urbanas, com população de vulnerabilidade social e sujeita a índices expressivos de violência. Procura proporcionar a tranquilidade 
e as condições básicas de educabilidade no ambiente escolar para que o processo de ensino e de aprendizagem aconteça. $\mathrm{O}$ desafio desse projeto consiste em repensar a escola, tornando-a mais aberta à participação da comunidade e mais inclusiva.

O universo dos participantes restringiu-se aos responsáveis pela gestão pedagógica das escolas (diretores, coordenadores pedagógicos e professores). Para a composição da amostra, foram selecionadas dez escolas e, de cada unidade, foram entrevistados: um diretor, um coordenador pedagógico, um professor de Língua Portuguesa e um professor de Matemática do Ensino Fundamental.

\subsection{Apresentação e análise dos dados}

\subsubsection{Diretores}

A visão que os diretores têm do SIMAVE reflete uma espécie de ambiguidade em relação à Secretaria de Estado de Educação de Minas Gerais (SEE/MG) e suas políticas de avaliação. De um lado, temos falas que respaldam o sistema avaliativo, reconhecendo nele uma boa tentativa de melhorar a gestão da escola. Para esses, as diretrizes adotadas estão corretas, embora acreditem que falte um pouco mais de envolvimento, por parte dos profissionais da educação, para que se tenham melhores resultados, conforme explicitado no comentário a seguir: “Apesar de termos uma boa política para monitoramento da qualidade, falta maior responsabilidade e comprometimento por parte dos profissionais da educação" (DIRETOR).

De outro lado, porém, há observações de que os problemas enfrentados pelas escolas (violência, indisciplina e descaso dos pais) estão longe de serem resolvidos por esses modelos de avaliação. Essas questões têm tamanho impacto sobre o cotidiano escolar que impedem, inclusive, uma maior eficiência do processo de ensino-aprendizagem: "Algumas diretrizes da SEE/MG são impossíveis de serem cumpridas pela escola em virtude da realidade que vive" (DIRETOR).

Nessa última fala, nota-se uma postura crítica em relação à gestão da educação feita pelas instâncias centrais. 
Alguns diretores manifestam o desconhecimento sobre a metodologia da avaliação. Eles destacam que alunos que optam por uma escolha aleatória das opções de resposta podem ter uma falsa boa nota, que dá a impressão de aquisição de habilidades:

Avaliações externas não refletem a realidade cognitiva do aluno que, em "um chute", pode acertar uma questão dando a falsa impressão de aquisição de habilidade. Em decorrência da questão da indisciplina, não se consegue nem trabalhar questões de aprendizagem cobradas pelo SIMAVE (DIRETOR).

Por outro lado, a maioria dos diretores admite que as atuais políticas educacionais têm contribuído para melhorias no processo de ensino-aprendizagem. Nesse sentido, o próprio SIMAVE estaria propiciando uma melhor medição da qualidade, tirando o professor de sua zona de conforto, obrigando-o a rediscutir seu trabalho, de acordo com as menções que se seguem:

O SIMAVE facilita a visualização do nível de aprendizagem do aluno e tira o professor da zona de conforto levando-o a repensar suas estratégias de atuação (DIRETOR).

Avaliações sistêmicas buscam apontar erros mais constantes e a partir daí contribuem para a melhoria da qualidade da educação (DRETOR).

A avaliação ajuda fazer diagnóstico, traçar metas e avaliar o processo de ensino-aprendizagem da escola (DIRETOR).

A avaliação fornece dados para o planejamento da escola (DIRETOR).

Em algumas falas fica patente a ideia de que existe uma lacuna na interlocução entre a instância gestora da política educacional, ou seja, a Secretaria do Estado de Minas Gerais, e a escola, como ilustra a fala abaixo: "Não há uma assessoria da Secretaria de Educação de Minas Gerais na tentativa de solucionar os problemas apontados pela avaliação sistêmica. A Secretaria dá o diagnóstico, mas não avança na busca de soluções" (DIRETOR).

A respeito das implicações dos resultados do SIMAVE sobre o 
trabalho da escola, existem situações bastante distintas nas escolas que vão desde a organização de reuniões que têm por finalidade discutir e traçar estratégias de melhoria, até a desmotivação por parte de diretores para um trabalho dessa natureza, sendo que, nesses casos, nem os resultados se tornam públicos.

\subsubsection{Coordenadores pedagógicos (supervisores ou orientadores)}

De acordo com os resultados da investigação, destacam-se nas falas dos coordenadores as seguintes questões: a violência, a indisciplina e a falta de autoridade dentro das escolas. Na totalidade das falas, destaca-se que:

As políticas educacionais não dão conta dos problemas enfrentados pela escola pelo próprio desconhecimento dos problemas reais que a escola enfrenta no seu cotidiano, tais como: descompromisso da família, falta de capacitação dos professores, ausência de política salarial, violência, falta de apoio aos projetos implantados pela SEE/MG, entre outros. (COORDENADOR PEDAGÓGICO).

As respostas apontam para a desvalorização da escola, sendo que a avaliação externa do sistema desconhece a sua realidade e destaca os seus pontos fracos sem levar em consideração os reais motivos que interferem na qualidade do ensino. No entanto, a maioria dos coordenadores reconhece a importância da avaliação como se pode perceber na citação abaixo: "Os sistemas de avaliação externa têm evoluído substancialmente, contribuindo para a reformulação do planejamento, os ajustes do currículo, a capacitação dos professores e a melhoria dos resultados do ensino público" (COORDENADOR PEDAGÓGICO).

Outros elementos surgiram na fala dos interlocutores em relação aos resultados do SIMAVE. Como a ação dos coordenadores é de apoio pedagógico aos professores, a forma com que a avaliação acontece deixa transparecer uma ação controladora por parte da equipe pedagógica, gerando assim uma insatisfação por parte do corpo docente. Nessa percepção, seis coordenadores justificaram a dificuldade de trabalhar com os resultados do SIMAVE. 
Ao abordarem a postura da SEE/MG em relação ao programa de avaliação, os coordenadores pedagógicos assinalaram algumas dúvidas em relação ao desempenho da Secretaria como atraso na divulgação dos resultados, falta de uma assessoria pedagógica, complexidade das tabelas e gráficos dos boletins pedagógicos.

\subsubsection{Professores}

De acordo com os resultados da investigação, alguns entrevistados afirmaram que a falta de participação dos professores na elaboração e nas discussões acerca da formulação das políticas públicas tem levado ao adoecimento profissional da categoria. Afirmam que há um distanciamento entre a realidade da escola e as propostas governamentais. Essas, muitas vezes, desconsideram questões que afetam o trabalho docente, levando os professores a uma busca solitária por soluções de problemas que são estruturais. Sendo assim, alguns professores denunciam: "As políticas educacionais têm servido mais de propaganda para o Governo do Estado do que, de fato, como busca para a solução dos graves problemas que afetam a escola" (PROFESSOR).

Por outro lado, alguns docentes afirmam que há um enfrentamento dos problemas através das políticas públicas, especialmente quanto ao diagnóstico das escolas, elaborados através dos resultados das avaliações sistêmicas, dos projetos e capacitações:

Algumas políticas públicas atuais, como Bolsa-Escola, têm contribuído para enfrentamento de alguns problemas como a pobreza. Também avaliações sistêmicas como o SIMAVE auxiliam na compreensão dos problemas enfrentados pela escola na questão da aprendizagem (PROFESSOR).

A aceitação e o envolvimento com o SIMAVE são manifestados na fala dos professores, como indica o trecho acima. Porém, há opiniões que apontam grandes lacunas nesse modelo de avaliação, como ilustra a fala abaixo:

As avaliações externas não refletem a realidade das escolas e nem mesmo a realidade cognitiva dos 
alunos que podem se sair bem nas avaliações, mas ter respondido "no chute". [...] a desconexão da avaliação com a realidade da sala de aula em que são desconsideradas as condições de trabalho dos professores e as condições de aprendizagem dos alunos interferem nos resultados (PROFESSOR).

Em contrapartida, houve um número significativo de profissionais que reconhecem o SIMAVE como:

Um excelente instrumento para diagnosticar a realidade da educação no Estado e a realidade da própria escola, oferecendo, através de seus dados, um diagnóstico preciso sobre o qual o professor pode se debruçar e construir seus planejamentos focados nas lacunas apontadas nos resultados que recebe (PROFESSOR).

Sendo assim, sugeriram um trabalho de continuidade que deveria acontecer após a divulgação dos resultados para as escolas. Esse trabalho envolveria a capacitação dos professores nas áreas em que foram detectadas necessidades de melhoria nos níveis de aprendizado. Além disso, consideraram essa forma de avaliação como importante instrumento para medir a qualidade da educação no Estado, destacando que a leitura e a interpretação dos resultados são acessíveis e de fácil compreensão.

Alguns professores, ao avaliarem os resultados referentes à escola na qual atuam, disseram considerá-los condizentes com o momento em que seus alunos se encontram, mas que, por outro lado, esses resultados não consideram a precária condição de alfabetização em que esses alunos chegaram até a escola e o grande desenvolvimento que tiveram a partir do trabalho realizado pelos professores.

Alguns professores, ao retratar a escola que trabalham perante outras escolas do Estado, demonstraram um descontentamento, como:

Os resultados da escola poderão estar abaixo do nível esperado. Contudo, se a análise é feita em relação ao avanço dos alunos desde que entraram naquela unidade e considerando a precariedade de condições em que chegaram, os resultados desta mesma escola se tornam excelentes (PROFESSOR). 
A maioria dos professores queixa-se de que o SIMAVE avalia, mas que não há uma assessoria da SEE/MG na tentativa de solucionar os problemas indicados pela avaliação, o que, na opinião deles, torna a avaliação uma medida ineficaz. Segundo eles, "dá o diagnóstico, mas não avança na busca de soluções" (PROFESSOR). Essa busca de soluções diz respeito a capacitações e auxílios pedagógicos nos aspectos que foram avaliados como desfavoráveis.

Em relação aos descritores usados na análise dos resultados, as opiniões dos professores são contraditórias:

Conhecer e trabalhar com os descritores dos resultados [...] a "prisão" a que os professores são submetidos quando se veem obrigados a desenvolver o seu trabalho com seus alunos em função apenas dos descritores para atender aos resultados da avaliação (PROFESSOR).

Analisando as outras falas dos professores, pode-se afirmar que as escolas divulgam os resultados da avaliação sendo os mesmos registrados em cartazes com identificação das médias obtidas e das metas a serem alcançadas. Mesmo assim, alguns professores afirmam que essa informação se dá de forma superficial e que seria necessário maior tempo para analisar os pontos levantados nas planilhas enviadas pela SEE/MG.

\section{Considerações finais}

A qualidade do ensino passa, a partir das reformas educacionais dos anos 90, a ser definida em função dos instrumentos de medida utilizados nos testes, sendo gerida pelas instâncias centrais de decisão. A avaliação é também dirigida à unidade escolar que poderá analisar os resultados, à luz de um panorama maior e de sua própria realidade, a partir dos conteúdos mínimos nela estabelecidos.

Todos esses fatores, componentes das avaliações sistêmicas, ao contrário de concluírem o propósito avaliativo, deveriam representar o ponto de partida para a busca da qualidade da educação no país.

As falas dos atores escolares que participaram da pesquisa remetem aos olhares que eles têm sobre a educação e o palco em que se desenvolve 
a prática pedagógica. As manifestações acabam por sintetizar o que aqueles que atuam no campo educacional entendem como sendo o seu principal desafio e como sendo a eficiência ou não das políticas que sobre eles atuam. Parece ser consenso a impressão de que a escola lida, hoje, com uma realidade social complexa que envolve graves questões sociais refletidas na violência, que acaba por ensejar a indisciplina e outros problemas. Tudo isso impactaria negativamente a dinâmica escolar e dificultaria o processo de ensino-aprendizagem na medida em que muito tempo seria gasto na solução desses problemas em detrimento do trabalho com conteúdos dos currículos escolares.

Reside aí um aspecto de crítica dos profissionais da educação em relação à política de avaliação sistêmica. Seguindo a lógica de que a escola enfrenta desafios que transcendem o simples trabalho com conteúdos escolares, vê-se como limitada uma política de avaliação que não leve em conta a complexidade da realidade presente na escola. Dessa forma, essa política estaria longe de ser uma solução para os problemas sociais importantes - como a violência e a negligência dos pais - que impactam negativamente a escola.

Ainda sobre o SIMAVE, os entrevistados constatam que as discussões que deveriam ser realizadas após a divulgação dos resultados são ainda insuficientes e os resultados são apresentados sem muita possibilidade de aprofundamento, pois a ênfase se situa mais nos gráficos, nas tabelas e nas metas em detrimento das dificuldades concretas existentes na realidade de cada escola.

O Estado, como maior interessado pelos resultados, mostra-se inoperante, cumprindo o papel de divulgador dos resultados sem, porém, apresentar soluções para os problemas detectados. Ao não participar efetivamente da resolução dos problemas, acaba apenas apontando o baixo rendimento em determinadas habilidades e competências, delegando para as escolas a tarefa de resolver os problemas de ensino da educação brasileira.

Nessa lógica, não se tem conseguido avaliar a importância do monitoramento de resultados a partir de um procedimento de avaliação sistêmica. Está aí presente uma falta de foco sobre o que deve ser o 
papel da escola: ocupar-se dos problemas sociais que se refletem nela ou ocupar-se da questão da aprendizagem dos conteúdos universalmente aceitos. Para alguns professores, o primeiro aspecto é tão premente que impede o trabalho com o segundo.

Fica evidente a dificuldade de interlocução entre os profissionais da escola e as instâncias centrais de planejamento. Não se conseguiu, no período de implementação dessa política, convencer os profissionais da educação de que, a despeito dos problemas enfrentados pela escola, eles devem eleger as avaliações sistêmicas como parâmetro do trabalho pedagógico a ser desenvolvido na escola.

Essa falta de convencimento tem feito com que os resultados apontados pelo SIMAVE figurem em planilhas e gráficos, mas não orientem efetivamente o trabalho da escola. Além disso, falta, segundo alguns entrevistados, uma assessoria mais efetiva das instâncias centrais como forma de auxiliar a escola no trabalho com esses resultados. Dessa forma, estaria a escola isolada sem saber ao certo como lidar com seus problemas e com os desafios explicitados pelas avaliações sistêmicas.

Apesar disso, um grande número de entrevistados manifestou-se favorável à avaliação como instrumento capaz de trazer melhorias para a educação no Estado e em suas escolas em particular, uma vez que seus trabalhos são norteados em função dos resultados do SIMAVE. Percebese aí um olhar que avalia o processo como ferramenta de melhoria da qualidade de ensino.

Esses profissionais demonstraram que pautam seu trabalho nos resultados da avaliação, preparando seus alunos para terem um bom desempenho e sua escola para alcançar as metas estabelecidas.

Destacamos que esse tema pode ser abordado a partir de outros enfoques, como a visão dos pais e alunos. Esses enfoques poderão contribuir para uma compreensão mais abrangente do SIMAVE e da forma como é visto pelos atores da comunidade escolar. 


\section{Referências}

ARELARO, L. R. G. A extensão do ensino básico no Brasil: ainda um desafio político. Em Aberto, Brasília, ano 7, n. 39, p. 35-43, jul./set. 1988.

ARROYO, M. G. Fracasso e sucesso: o peso da cultura escolar e do ordenamento da educação básica. Em Aberto, Brasília, ano 11, n. 53, p. 46-53, jan./mar. 1992.

AZEVEDO, J. M. Lins. A educação como política pública. Campinas, SP: Autores Associados, 1997.

BONETTI, L. W. Políticas públicas por dentro. Ijuí, RS: Unijuí, 2006.

CAMPOS, M. M. M. Escola e participação popular: a luta por educação elementar em dois bairros de São Paulo. Orientadora: Aparecida Joly Gouveia. Tese (Doutorado em Ciências Sociais) - Faculdade de Filosofia, Letras e Ciências Humanas, Universidade de São Paulo, São Paulo, 1983.

CARDOSO, M. L. Ideologia da globalização e (des)caminhos da Ciência Social. In: GENTILI, P. (Org.). Globalização Excludente. Desigualdade, exclusão e democracia na nova ordem mundial. Petrópolis: Vozes, 1999. p. 96-127.

DEUTSCH, K. Política e governo. Brasília: Ed. Universidade de Brasília, 1984.

FRIGOTTO, G.; CIAVATTA, M. Educação Básica no Brasil na década de 90: subordinação ativa e consentida à lógica do mercado. Educação e Sociedade, Campinas, v. 24, n. 82, 2003.

GRAMSCI, A. A concepção dialética da história. Rio de Janeiro: Civilização Brasileira, 1978. 
MELLO, G. N. de. Cidadania e competitividade: desafios educacionais do terceiro milênio. São Paulo: Cortez, 1992.

MINAS GERAIS. Constituição (1989). Constituição do Estado de Minas Gerais. Belo Horizonte: Inédita, 2001.

. Orientações para o planejamento de um projeto estruturador. Versão 4 (05/02/2004). Belo Horizonte: SEPLAG, 2004.

OLIVEIRA, D. A. A gestão democrática da educação no contexto da reforma do estado. In: FERREIRA, N. S. C.; AGUIAR, M. Â. da S. Gestão da Educação: impasses, perspectivas e compromissos. São Paulo: Cortez, 2001.

SANTOS, L. L. de C. P. Políticas públicas para o ensino fundamental: parâmetros Curriculares Nacionais e Sistema Nacional de Avaliação (SAEB). Educação e Sociedade, Campinas, v. 23, n. 80, p. 346-367, set. 2002.

UNESCO. Declaração Mundial sobre Educação para Todos: Satisfação das Necessidades Básicas de Aprendizagem. Conferência Mundial de Educação para Todos. Jomtien, Tailândia, 5 a 9 de março de 1990.

WEBER, S. Políticas educacionais, práticas escolares e objetivos de aprendizagem: repercussões na sala de aula. In: LISITA, V. M. S. de S.; SOUSA, L. F. E. C. Políticas educacionais, práticas escolares e alternativas de inclusão escolar. Rio de Janeiro: DP\&A, 2003.

WEFFORT, F. Qual democracia? São Paulo: Cia das Letras, 1992. 


\title{
The Assessment System of Public Education in Minas Gerais: perceptions of public school professional in Belo Horizonte
}

\begin{abstract}
This article analyzes the results of the survey: "A view of the public schools in Minas Gerais about SIMAVE's results", developed by the Center of Studies and Research on Educational Policy (FAE/ UEMG). It deals with the centrality of systemic assessment in the Brazilian educational scenario and its implications for pedagogical staff who work in schools: principals, coordinators and teachers. Initially, it discusses the implementation process of systemic assessment in the country by rescuing of the historical conjuncture Brazil in and the world. In a second moment, the article focuses on the perceptions of the school staff involved in the assessment process SIMAVE.
\end{abstract}

Keywords: systemic assessment; educational policy; educational reform; educational institution.

Recebido: 19/05/11

Aprovado: 24/10/11 